\title{
INDUÇÃO DE RESISTÊNCIA EM Manihot esculenta AO ATAQUE DE Aleurothrixus aepim
}

\section{INDUCTION OF RESISTANCE IN Manihot esculenta THE ATTACK OF Aleurothrixus aepim}

Gemerson Machado de Oliveira ${ }^{1}$; Adelaido de Araújo Pereira ${ }^{2}$; Heloísa Martins de Araújo ${ }^{3}$; Jacinto de Luna Batista ${ }^{4}$

DOI: https://doi.org/10.31692/978-65-991061-7-0.329-333

\section{INTRODUÇÃO}

Em 2014 a produção nacional de mandioca ultrapassou 23 milhões de toneladas de raiz (AGRIANUAL, 2015). Segundo a Fao (2013) a mandioca tornou-se uma cultura versátil que atende as prioridades dos países em desenvolvimento, as tendências da economia global e ao desafio das mudanças climáticas.

Apesar de sua importância, a mandioca não vem apresentando, um padrão estável de produtividade ao longo do tempo, principalmente na área produzida, verificando-se perdas significativas através de doenças e insetos. Dentre os principais insetos causadores de danos a cultura da mandioca encontra-se a Aleurothrixus aepim (Goeldi, 1886) e o percevejo-derenda, Vatiga illudens (Drake, 1922) (Hemiptera: Tingidae) succionam a seiva das plantas, provocando queda das folhas, causando redução da fotossíntese, comprometendo a produtividade de raízes e da parte aérea (FARIAS e BELLOTTI, 2006).

Têm-se buscado alternativas que visem atender de forma rápida, ao mesmo tempo que gerem baixo custo econômico e que sejam eficiente no controle de pragas, gerem aumento da produtividade com baixo impacto ao meio ambiente. Diante desta perspectiva surge a possibilidade da utilização do silício em pulverização, com a finalidade no controle de insetos-pragas, como também a aplicação via aplicação foliar (CAMARGO, 2011). Objetivou-se com essa pesquisa avaliar o efeito da aplicação foliar de silicato de potássio em M. esculenta, visando a indução de resistência ao ataque de A. aepim.

\section{FUNDAMENTAÇÃO TEÓRICA}

Considerando o impacto provocado por esses insetos-praga, o longo ciclo vegetativo

\footnotetext{
${ }^{1}$ Mestrando em Agronomia, Programa de Pós-Graduação em Agronomia (PPGA), Centro de Ciências Agrárias (CCA) da Universidade Federal da Paraíba (UFPB), e-mail: gemerson.agro@gmail.com

${ }^{2}$ Mestre em Agronomia, Engenheiro Agrônomo, e-mail: adelaido-p@ hotmail.com

${ }^{3}$ Graduação em Agronomia, Centro de Ciências Agrárias (CCA) da Universidade Federal da Paraíba (UFPB), email: heloiisa.martiins@gmail.com

${ }^{4}$ Professor Associado IV, Programa de Pós-Graduação em Agronomia (PPGA), Centro de Ciências Agrárias (CCA) da Universidade Federal da Paraíba (UFPB), e-mail: jacinto@cca.ufpb
} 
da mandioca e a falta de defensivos que possam ter efeito por todo ciclo da cultura, busca-se utilizar produtos alternativos que atenda essa necessidade, e nesse sentido pesquisas veem demostrando resultados favoráveis com a aplicação de silício, a aplicação podendo dificultar a penetração dos estiletes do inseto-praga no tecido da planta (CAMARGO et al., 2011). Ainda, segundo Sá et al. (2015) aplicação, via foliar, de concentrações de silicato de potássio promoveu plantas de mamoeiro mais vigorosos, com menos estresse a fatores bióticos e abióticos, tendo na indução de resistência uma alternativa para o controle de insetos-praga.

A correção da deficiência nutricional das culturas é realizada através de adubação, por meio de fertilizantes, os quais sendo à base de silício são mencionados na literatura como indutores resistência (DATNOFF et al., 2001). Através da adubação foliar de silício ocorreu a proteção às plantas de amendoim, com a redução do número de adultos e ninfas do tripes Enneothrips flavens, além de aumentar a produtividade da cultura do amendoim em 31,30 \% em casca e 28,85 em grãos (DALASTRA et al., 2011).

\section{METODOLOGIA}

O experimento foi conduzido na Comunidade Sítio Pirpiri, município de Mari, Paraíba, no período 21 de junho de 2014 a 25 de janeiro de 2015. De acordo com a classificação de Köppen (Brasil, 1972), o clima nessa região é quente e úmido com chuvas de outono-inverno, região bioclimática $3 \mathrm{~b}$ Th. O solo é classificado como Argissolo VermelhoAmarelo.

O delineamento experimental utilizado foi em blocos casualizados (DBC), com cinco repetições e cinco níveis de $\mathrm{K}_{2} \mathrm{SiO}_{3}$, constituído dos seguintes arranjos: (N1), 0,0\% $\mathrm{K}_{2} \mathrm{SiO}_{3}$; $\left(\mathrm{N}_{2}\right) \quad 0,5 \% \quad \mathrm{~K}_{2} \mathrm{SiO}_{3} ;\left(\mathrm{N}_{3}\right) \quad 1,0 \% \mathrm{~K}_{2} \mathrm{SiO}_{3} ;\left(\mathrm{N}_{4}\right) \quad 1,5 \% \mathrm{~K}_{2} \mathrm{SiO}_{3}$ e $\left(\mathrm{N}_{5}\right) \quad 2,0 \% \mathrm{~K}_{2} \mathrm{SiO}_{3}$. No plantio foram abertas covas de $0,10 \mathrm{~m}$ de profundidade e $0,60 \mathrm{~m}$ de distância entre si, onde se colocaram as manivas sementes com 0,20 m de comprimento e plantadas horizontalmente na parte superior do leirão, cada parcela experimental foi composta por cinco leirões de 3,00 m de comprimento, espaçados de 1,20 m entre leirões e 0,60 m entre plantas sendo a área útil da parcela de 3,60 $\mathrm{m}^{2}$, composta por 25 plantas da variedade de mandioca "tunhia". Para as variáveis estudadas foram consideradas apenas os três leirões centrais, sendo avaliadas três plantas e escolhida uma folha do terço médio e uma do terço inferior para avaliações quinzenais.

Foi realizada aplicação foliar com silicato de potássio aos 20 dias após a brotação (DAB) e $80 \mathrm{DAB}$ com pulverizador costal eletrônico até atingir o ponto de escorrimento, compreendendo dois períodos, até completar o $4^{\circ}$ mês de brotação. 
Foram coletadas três folhas por tratamento para avaliação da infestação do número de ninfas e adultos da Aleurothrixus aepim.

Figura 1. Dados pluviométricos durante o período experimental nos anos de 2014 (A) e 2015 (B). Fonte: Emepa-PB, 2015.

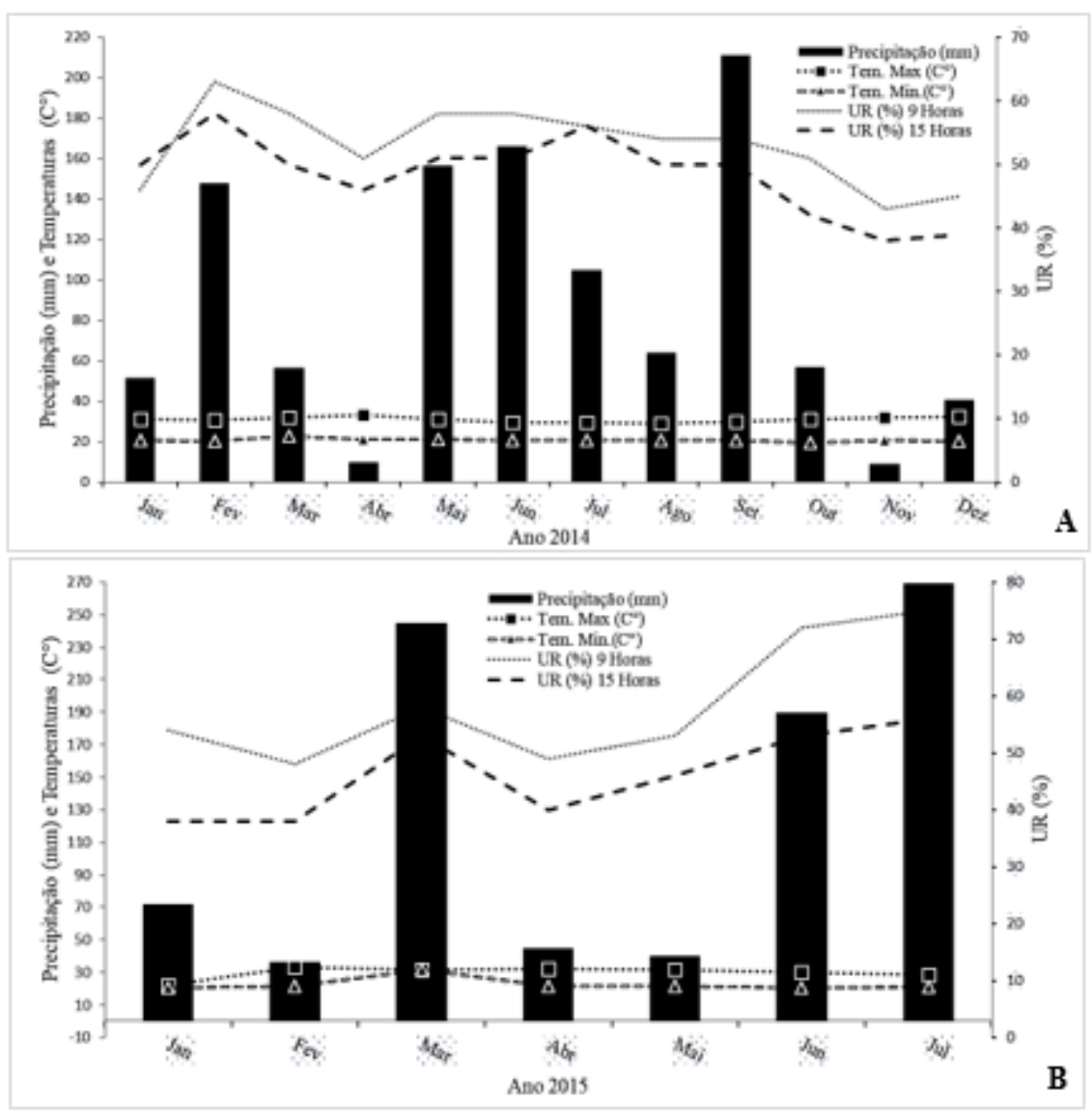

Para análise estatística utilizou-se o programa SISVAR® (Sistema de Análise de Variância para Dados Balanceados), desenvolvido por Ferreira (2014) e a comparação de médias pelo teste ao teste de Duncan, tendo os dados de contagem subı $\mathbf{B}$ dos à transformação: raiz quadrada de y +0,5 - SQRT $(y+0,5)$ ou seja $\sqrt{ }(x+0,5)$, em nível de $5 \%$ de probabilidade, para a comparação das médias.

\section{RESULTADOS E DISCUSSÕES}

Dos níveis em épocas de aplicação avaliados, Não houve diferenças estatísticas para número médio de ninfa e adultos de A. aepim (Tabela 1). Em todos os níveis de aplicação tanto para número de ninfas e adultos de mosca-branca não mostraram diferenças significativas 
Tabela 1. Número médio de ninfas e adultos de Aleurothrixus aepim, em duas épocas de aplicação de $\mathrm{K}_{2} \mathrm{SiO}_{3}$. Fonte Própria.

Medias seguidas, de mesma letra minúscula na coluna diferem entre si a $5 \%$ de probabilidade pelo teste de

Número de inseto/planta

\begin{tabular}{|c|c|c|c|c|}
\hline \multirow[t]{2}{*}{ Tratamento } & \multicolumn{2}{|c|}{ Primeira Aplicação (20 DAB) } & \multicolumn{2}{|c|}{ Segunda Aplicação (80 DAB) } \\
\hline & NIF & $\mathrm{AD}$ & NIF & $\mathrm{AD}$ \\
\hline $0,0 \%$ de $\mathrm{K}_{2} \mathrm{SiO}_{3}$ & $20,380 \mathrm{a}$ & $4,891 \mathrm{a}$ & $96,400 \mathrm{a}$ & $2,172 \mathrm{a}$ \\
\hline $0,5 \%$ de $\mathrm{K}_{2} \mathrm{SiO}_{3}$ & 20,937 a & $5,425 \mathrm{a}$ & $90,800 \mathrm{a}$ & $2,600 \mathrm{a}$ \\
\hline $1,0 \%$ de $\mathrm{K}_{2} \mathrm{SiO}_{3}$ & $18,315 \mathrm{a}$ & $4,769 \mathrm{a}$ & $94,600 \mathrm{a}$ & $1,375 \mathrm{a}$ \\
\hline $1,5 \%$ de $\mathrm{K}_{2} \mathrm{SiO}_{3}$ & 18,660 a & $4,772 \mathrm{a}$ & $89,000 \mathrm{a}$ & $1,530 \mathrm{a}$ \\
\hline $2,0 \%$ de $\mathrm{K}_{2} \mathrm{SiO}_{3}$ & $19,519 \mathrm{a}$ & $4,997 \mathrm{a}$ & $61,200 \mathrm{a}$ & $1,436 \mathrm{a}$ \\
\hline CV (\%) & 21,72 & 25,83 & 28,14 & 48,13 \\
\hline
\end{tabular}

Duncan.

Dados transformados a $\sqrt{x}+0,5$.

nif: ninfa; ad:adultos.

Os resultados obtidos para o número médio de ninfas de mosca branca não foram significativos tanto para primeira aplicação como para segunda aplicação, no entanto ocorreu decréscimo nos valores absolutos, Silva et al., (2010) confirmaram tais resultados no qual foi encontrado efeito não significativo do silício em repolho para controle da traça-das-crucíferas Plutella xylostella (L., 1758) (Lepidoptera: Plutellidae). Resultados semelhante foram encontrados também por Redmond e Potter (2007) os quais não encontraram efeito significativo sobre o inseto ou sobre o dano à planta, embora trabalhando com Bemisia tabaci biótipo B, Moraes et al. (2009) encontrou em cultivar de soja moderada resistência.

\section{CONCLUSÕES}

A aplicação de silicato de potássio não afeta os números de insetos jovens de Aleurothrixus aepim; Aplicação de silicato de potássio, após dois meses de brotação de manivas não interfere no número de insetos jovens ou adultos de Aleurothrixus aepim Aleurothrixusaepim.

\section{REFERÊNCIAS}

AGRIANUAL. Anuário da Agricultura Brasileira, São Paulo: Instituto FNP, 2015. 472p.

CAMARGO, J. M. M. Seleção de clones, absorção e translocação de silício, e seu efeito sobre a população do psilídeo-de-concha Glycaspis brimblecombei (Moore) (Hemiptera: Psyllidae) em plantas de Eucalyptus camaldulensis Dehn. (Tese de Doutorado), Curitiba: 
Programa de Pós-Graduação em Ciências Biológicas/UFPR, 2011, 104 f.

FAO, Food and Agriculture Organization of the United Nations. Produzir mais com menos: Mandioca: um guia para a intensificação sustentável da produção. Rome, 2013 b. Disponível em: < http://www.fao.org/ag/save-and-Grow/cassava/pdf/FAOMandioca.pdf >. Acesso em: 26 ago. 2014.

FERREIRA, D. F. Sisvar: a Guide for its Bootstrap procedures in multiple comparisons. Ciênc. agrotec. [online]. 2014, vol.38, n.2 [citado 2015-10-17], pp. 109-112. Disponibleen: ISSN 1413-7054. http://dx.doi.org/10.1590/S1413-70542014000200001.

DALASTRA, C.; CAMPOS, A. R.; FERNANDES, F. M.; MARTINS, G. L. M.; CAMPOS, Z. R. Silício como indutor de resistência no controle de tripes do prateamento Enmeothrips flavens Moulton, 1941 (Thysanoptera: Thripidae) e seus reflexos na produtividade do amendoinzeiro. Ciência e Agrotecnologia, Lavras, v. 35, n. 3, p. 531-538, 2011.

DATNOFF, L. E.; SEEBOLD, K. W.; CORREIA, V. F. J. The use of silicone for integrated disease management: reducing fungicide applications and enhancing host plantresistance. In: DATNOFF, L. E.; SNYDER, G. H.; K----, G. H. Silicon in agriculture. Netherlands: Elsevier Science, 2001. P. 171 - 183.

FARIAS, A. R. N.; BELLOTTI, A. C. Pragas e seus controles. In: SOUZA, L. S.; FARIAS, A. R. N.; MATTOS, P. L. P.; FUKUDA, W. M. G. (Ed.). Aspectos socioeconômicos e agronômicos da mandioca. Cruz das Almas: Embrapa Mandioca e Fruticultura Tropical, 2006. Cap.20, p.591-671.

MORAES, J. C.; FERREIRA, R. S.; COSTA, R. R. Indutores de resistência à mosca-branca Bemisia tabaci biótipo B (Genn., 1889) (Hemiptera: Aleyrodidae) em soja. Ciência e Agrotecnologia, Lavras, v. 33, n. 5, p. 1260-1264, set./out. 2009.

REDINOND, C. T.; POTTER D. A. Silicon fertilizantion does not enhance creeping bentgrass resistance to cutworms and white grubs. USGA Turfgrassande Environmental Research, Lakeland, v. 6, p. 1-7, 2007.

SÁ, F. V. S.; ARAÚJO, J. L.; OLIVEIRA, F. S.; SILVA, L. A.; MOREIRA, R. C. L.; SILVA NETO,A. N.C. Influence of silicon in papaya plant growth. Científica, Jaboticabal, v.43, n.1, p.77-83, 2015.

SILVA, A. L. S. JUNQUEIRA, A. M. R.; FREITAS, L. M.; SILVA, F. A. S. Efeito da aplicação de silício na incidência da traça-das-crucíferas em repolho. Horticultura Brasileira, Brasilia, v. 28, n. 2, (suplemento-CD Rom), 2010. 